Irena Selišnik

\title{
MATEJA SEDMAK IN ZORANA MEDARIČ (UR.): MED JAVNIM IN ZASEBNIM. ŽENSKE NA TRGU DELA.
}

Koper:Univerza na Primorskem, Znanstveno-raziskovalno središče, Založba Annales: Zgodovinsko društvo za južno Primorsko, zbirka Annales Majora, 2007, 316 strani.

Knjiga, ki je izšla pri založbi Annales, nam predstavi eno najbolj problematičnih področji $\mathrm{v}$ okviru problematike enakosti spolov. Trg dela in ženske ter usklajevanje zasebnega oziroma družinskega in profesionalnega življenja je zagotovo ena izmed prioritet sodobne politike v oblikovanju bolj demokratične in enakopravne družbe, ne le v Sloveniji, pač pa tudi v Evropski uniji. Kljub novim ukrepom, ki se spopadajo s starimi strukturami in vzorci mišljenja, pa podatki o strukturi trga dela še vedno kažejo horiziontalno in vertikalno segregacijo po spolu ter izrazito feminizacijo nekaterih poklicev. Uresničevanje zastavljenih ciljev iz akcijskih načrtov in nacionalnih programov tako ostaja izmikajoči se namen, ki med drugim šepa tudi zaradi pomanjkljivega poznavanja specifične problematike in prav v tem kontekstu je knjiga Med javnim in zasebnim. Ženske na trgu dela. zelo dobrodošla pridobitev.
Delo je oblikovano kot zbornik, v katerem priznane strokovnjakinje, ki se že vrsto let ukvarjajo s problematiko spola in poklicnega življenja, predstavljajo svoja dosedanja dognanja. Na enem mestu so tako zbrani ključni članki, ki iz različnih zornih kotov osvetljujejo različne vidike raziskovanja problematike zaposlovanja žensk, njihovih vlog in položaja na trgu delovne sile, izgradnjam karierne poti in usklajevanjem poklica $\mathrm{z}$ družinskim in partnerskim življenjem. Delo se tako začne $z$ nekakšnim preludijem $\mathrm{v}$ današnjo situacijo in strukturam, ki obvladujejo sodobno vsakodnevno poklicno in družinsko življenje. Sabina Žnidaršič Žagar v svojem prispevku prikaže historično perspektivo na oblikovanje trga delovne sile ter si v prispevku zada tudi doslej nerešeno vprašanje, zakaj so ženske $\mathrm{v}$ slovenskem prostoru bile vedno $\mathrm{z}$ nadpovprečnim deležem $\mathrm{v}$ 
evropskem kontekstu zastopane na trgu delovne sile.

Sledita prispevka, ki se ukvarjata s specifično ciljno skupino - mladimi in njihovimi zaposlitvenimi možnostmi ter vplivom njihove zaposlitve na odločitev za družinsko življenje. Darka Podmenik in Nevenka Černigoj Sadar v svojem tekstu $V$ iskanju izmikajočega se cilja obravnavata eno najbolj perečih težav sodobne slovenske družbe. Mlade iskalke prve zaposlitve so tako leta 2004 prevladovale med vsemi registriranimi brezposelnimi ženskami, zaskrbljujoč pa je tudi trend naraščanja števila brezposelnih iskalk prve zaposlitve. Avtorici sta v svojem članku, ki se osredotoča zlasti na mlade študentke in diplomantke družboslovnih in humanističnih visokošolskih usmeritev, ponudili razlage tega fenomena, pa tudi predloge za ukrepe za zagotavljanje enakosti spolov pri zaposlovanju. Z vprašanjem prve zaposlitve je tesno povezana tudi odločitev za formiranje lastnega gospodinjstva in družine, korelacija med dejavniki pa sta v svojem članku Vpliv zaposlitve na družinske odločitve in družinsko življenje podrobneje predstavili Mateja Sedmak in Zorana Medarič. Usklajevanje obeh sfer življenja predstavlja enega izmed največjih izzivov mladim ženskam, ki se v različnih okoljih s temi izzivi spoprijemajo $\mathrm{z}$ različnimi strategijami.

$\mathrm{V}$ nadaljevanju so $\mathrm{v}$ zborniku zbrani prispevki, ki obravnavajo specifične problematike posameznih poklicnih skupin žensk. Predstavljeni so njihovi odzivi na probleme $s$ katerimi se srečujejo na trgu delovne sile in načini $s$ katerimi rešujejo konflikte med profesionalno kariero in družinskim oziroma partnerskim življenjem. V prispevku Milice Antić Gaber so tako orisane poklicne kariere slovenskih političark. $\mathrm{Na}$ tradicionalno par excellence moškem področju je tako zastopanost žensk skromna, avtorica pa nas seznani s strategijami, ki so jih za vstop v politiko uporabile slovenske poslanke. Te so od poslancev v marsičem različne, v glavnem tako vstopijo v tovrstno poslanstvo starejše, imajo manj otrok in se odločajo za aktivnejši angažma pri obravnavi socialnih vprašanj. Profil slovenske političarke se tako ujema s spoznanji podobnih raziskav $\mathrm{v}$ tujini, ki potrjujejo, da družina in otroci ostajajo problem profesionalne ali politične kariere žensk. V mnogočem je $\mathrm{z}$ visoko cenjenim poklicem političarke primerljiv tudi poklicni status znanstvenic. Ženske, ki se odločijo za tovrstne poklicne poti na- 
letijo na številne ovire na poti do realizacije svojih ciljev, ki so povezane s posegi v »moške trdnjave«. Maca Jogan je v svojem tekstu tako podrobneje obravnavala ravno »oviro« usklajevanja družinskega in profesionalnega življenja, ki je z znanstvenice še vedno tudi institucionalno, pa žal tudi kulturno pogojeno. V nadaljevanju zbornika je Renata Šribar predstavila posebno skupino znanstvenic, zasebne raziskovalke. Slednje delujejo v dvakratno diskriminatornih razmerah, sprva zaradi spola in nato zaradi svoje pozicije kot posebna alternativa razmerju med vednostjo in oblastjo.

Prav tako specifična poklicna skupina so tudi ženske, ki zasedajo menedžerske položaje in, ki so predstavljene $\mathrm{v}$ članku Aleksandre Kanjuo Mrčela. Tudi tu so tovrstni položaji močno maskulinizirani, ženske pa v neenakem položaju glede na moške tudi v dostopu do najvišjih pozicij. Tovrstni neformalni mehanizmi, močnih in težko premagljivih ovir za mobilnost po lestvici napredovanja so predstavljeni s pomočjo metafor, razlag steklene arhitekture sodobnih organizacij. "Požrešna« organizacijska kultura dominantne moškosti (dolgih delovnikov in neformalnih mrež) tako v Sloveniji kot v ostalih delih Evrope ohranja vertikalno in horizontalno segregacijo po spolu na trgu dela, kljub temu, da ženske v povprečju dosegajo višjo izobrazbeno stopnjo in usposobljenost kot moški. Toda visoko motivirane in "pridne« ostajajo $\mathrm{v}$ feminiziranih nižje plačanih in spoštovanih poklicih. Utelešenje tovrstne profesije predstavlja prav poklic učiteljice oziroma vzgojiteljice, ki ga v svojem prispevku Poklic posebne vrste predstavljata Ana Kralj in Tanja Rener. V učiteljski poklic je tako še vedno prvenstveno poklicana ženska, saj le ta predstavlja izraz njenega prvega poklica - materinstva, hkrati pa država kot glavna delodajalka institucionalizira feminizacijo učiteljskega poklica. Ravno v Sloveniji je feminizacija šolstva višja od povprečja v ostalih državah članicah EU, država pa z umestitivijo poklica med prekarna dela tovrstnega položaja po vsej verjetnosti še dolgo ne bo spremenila.

Razkorak med normami zapisanimi v zakonodajnih dokumentih in konkretno implementacijo politik pa ni očiten le na problemu socialnega varstva učiteljic, pereč je tudi v primeru gospodinjskih pomočnic. Zbornik tako zaključujeta dva prispevka na to temo, ki v Sloveniji doslej še ni bila velikokrat obravnavana. Majda Hrženjak tako predstavlja 
strukturne značilnosti sodobnega neformalno plačanega reproduktivnega dela $v$ domačem in mednarodnem kontekstu in nam naniza primere praks iz evropskih držav, ki so neformalno reproduktivno delo legalizirale in ga zakonsko opredelile. Dilema ureditve plačanega domačega dela je vsekakor dvorezen meč, ki tovrstne dejavnosti sicer res naredi "vidne« in zmanjša možnosti izkoriščanja, hkrati pa njegova profesionalizacija marginalizira določene družbene skupine. Zato je še posebej pomembno, da je poseg države v tovrstna razmerja premišljen. Da pa bi država resnično "pametno" posredovala, pa so potrebne natančnejše analize populacije, ki tovrstno delo opravlja. In prav v ta kontekst vstopi prispevek Zdenke Šadl, ki podrobneje obravnava populacijo žensk, ki se odločajo za delo na tujem domu. Podobno kot ostali teksti se tudi ta spušča na raven beleženja tistega, kar je zmuzljivo in empirično težko dokazljivo, neformalnih mehanizmov diskriminacije. Eden izmed tako težko opredeljivih fenomenov je tudi razvoj kvazi družinskih relacij med gospodinjsko pomočnico in delodajalko.

Delo Med javnim in zasebnim. Ženske na trgu dela je vsekakor zanimivo branje, saj so na enem mestu prvič zbrane slovenske študije o posameznih poklicnih skupinah žensk, ki jih lahko povsem neproblematično umestimo tudi v evropski kontekst raziskav žensk na trgu delovne sile. Poleg tega se lahko vsaka bralka, glede na visoko zaposlenost žensk v Sloveniji, prepozna v katerem izmed prispevkov, bralci pa ugotovijo povsem novo perspektivo na dano situacijo. Prispevki ponujajo tudi nadaljnje iztočnice za bodoča raziskovanja prisotnosti žensk na trgu delovne sile, saj bi veljajo marsikaterega nadgraditi $z$ nadaljnjimi študijami ter tako ovrednotiti slovenske posebnosti. Priporočila in dobre prakse, ki bi lahko izboljšale položaj žensk na trgu delovne sile, navkljub zaskrbljujočim trendom po katerih strukturna neenakost med spola vztraja, bi namreč vsekakor veljalo pridobiti in jih tudi upoštevati ter učinkovito implementirati. 